\title{
A review of giardiasis and its parasite genotypes in Iran
}

\author{
Faham Khamesipour, ${ }^{1}$ Bahareh Chelgerdi Dehkordi, ${ }^{2}$ Sana-Sadat Afzal, ${ }^{2}$ Pariya Kheyri, ${ }^{2}$ \\ Saeed Nezaratizadeh, ${ }^{2}$ Shadan Shojaat, ${ }^{2}$ Seyed Hossein Hejazi ${ }^{3,4}$ \\ ${ }^{1}$ Student Research Committee, Shahid Beheshti University of Medical Sciences, Tehran; ${ }^{2}$ Shahrekord \\ Branch, Islamic Azad University, Shahrekord; ${ }^{3}$ Department of Parasitology and Mycology, School of \\ Medicine, Isfahan University of Medical Sciences, Isfahan; ${ }^{4}$ Skin Diseases and Leishmaniasis Research \\ Center, Department of Parasitology and Mycology, School of Medicine, Isfahan University of Medical \\ Sciences, Isfahan, Iran
}

\begin{abstract}
Giardia lamblia is one of the most prevailing intestinal protozoa in many vertebrates like humans, domestic and wild animals. Molecular studies show that Giardia lamblia is a complex parasite. Currently, giardiasis disease is one of the main problems of social and personal health in different countries around the world. Giardia is known as a zoonotic parasite that is divided into eight genetic assemblages (A to $\mathrm{H}$ ). In this review study, by referring to the molecular epidemiology of Giardia lamblia and emphasizing its zoonotic factors, the background of Giardia and its genotypes in Iran have been studied. The study population consisted of indexed articles in reputable databases such as Scopus, Magiran, SID, Science Direct, PubMed, and Google Scholar in Iran from 1990 to 2020. Based on limited studies in Iran, assemblage BIII
\end{abstract}

Correspondence: Bahareh Chelgerdi Dehkordi, Faculty of Veterinary Medicine, Shahrekord Branch, Islamic Azad University, Shahrekord, Iran, PO Box 166.

E-mail: baharchelgerdi@gmail.com

Key words: Giardia; genotype; assemblage; prevalence; Iran.

Acknowledgments: The authors would like to thank Mrs. Sakineh Akbari and Miss Bahareh Basirpour for assistance in gathering information.

Conflict of interest: The authors have no conflict of interest to declare.

Availability of data and materials: All data generated or analyzed during this study are included in this published article.

Ethics approval and consent to participate: Not applicable.

Informed consent: Not applicable.

Received for publication: 30 November 2020.

Revision received: 27 May 2021.

Accepted for publication: 14 June 2021.

This work is licensed under a Creative Commons Attribution NonCommercial 4.0 License (CC BY-NC 4.0).

(C) Copyright: the Author(s), 2021

Licensee PAGEPress, Italy

Infectious Diseases and Herbal Medicine 2021; 2:126

doi:10.4081/idhm.2021.126 and AII are the most common types of Giardia assemblages. Therefore, it is necessary to conduct comprehensive studies on various human and animal isolates in different areas of the country, especially places where no researches have been done.

\section{Introduction}

Giardia parasite is an intestinal protozoan in humans and a wide range of vertebrate hosts. ${ }^{1}$ This organism is one of the ten major parasites of human and one of the most prevailing non-viral causes of diarrhea in humans and domestic ungulates. ${ }^{2,3}$ Giardia duodenalis is the only species found with a zoonotic significance. ${ }^{4}$ This parasite has two different forms in its life cycle. The first form is a flagellate trophozoite that lives in the upper part of the small intestine and causes clinical symptoms. The other form is two or four nuclei cysts that excrete with the host feces and remain in the environment for weeks. The disease transmission occurs through a person to another or through contaminated water and food. Although this protozoan has been reported from all over the world, it is more prevalent in tropics and areas with few health facilities and high populations. ${ }^{3}$

In developing countries, the rate of prevalence and incidence of giardiasis infection is high. It is estimated that about 200 million people in Asia, Africa, and Latin America are infected by symptomatic giardiasis, and about 500,000 new cases are reported annually. ${ }^{2}$ Clinical symptoms of the disease are varied from asymptomatic infections to chronic diarrhea. Symptomatic cases are usually accompanied by weakness, weight loss, watery diarrhea, stinky stools, fatty or steatorrhea diarrhea, abdominal cramps, abdominal bloating, burping, nausea, vomiting, and malabsorption syndrome. ${ }^{3,5,6}$ Allergic skin manifestations like urticaria and angioedema are the other symptoms. ${ }^{6-8}$

There is little information about the risk factors of giardiasis, some of them include the status of the immune system, age, sex, and environmental, social, economic, occupational, and nutritional conditions, and recently the type of genotypes. ${ }^{9-17}$ Although relatively numerous and scattered studies have been performed by Iranian researchers on giardiasis in Iran, still the current status of this disease is not exactly clear. Therefore, this study is designed for awareness of the status of this disease in Iran. This review presented articles related to giardiasis and its various epidemiological aspects in Iran using keywords, Giardia, giardiasis, genotype, assemblage, prevalence, Iran (alone or in combination) have been searched in reputable and accessible information databases like Science Direct, SID, Scopus, and Magiran from 1990 to 2020. 


\section{Species and genome}

Several species of Giardia have been defined based on differences in morphological features and specific hosts including Giardia duodenalis, Giardia muris, Giardia agilis, Giardia ardeae, Giardia psittaci, and Giardia microti (Appendix, Table 1).

Among them, Giardia duodenalis (synonym with Giardia intestinalis or Giardia lamblia) is the only species detected in humans. ${ }^{8}$ Possibly rare parasite species similar to Giardia duodenalis is present in reptiles.

Although reported Giardia in lizards lacks a median body and two nuclei cysts, it is considered as Giardia varani. ${ }^{18}$ Giardia duodenalis genome is estimated at approximately $2.2 \times 10^{7} \mathrm{bp}$, and its $\mathrm{C}+\mathrm{G}$ content $49 \%$. This genome has four central histones commonly used in eukaryotes to form chromosomal DNA. ${ }^{19}$

\section{Target genes}

Although simple methods have been introduced to identify Giardia in clinical and environmental specimens, recently various molecular tools have been used to differentiate this parasite by species, assemblage (subspecies), and genotype. In this regard, different target genes are used, which GDH (Glutamate dehydrogenase), SSU rRNA Vsp (Variant surface protein), TPI (Triose-phosphate isomerase), and BG ( $\beta$-giardin) have more use. By reviewing the studies of researchers, we found that the SSU rRNA gene is mostly used to differentiate species and assemblages, and the TPI gene (with the highest number of variable locus) for parasite subtypes. But in general, the GDH and BG genes are more widely used than other target genes. ${ }^{19-23}$

Based on various molecular methods such as PCR-RELP and sequence analysis, Giardia duodenalis is divided into three genotypes named groups 1, 2, 3 (WB, JH, GS). In conducted studies, Giardia isolates divides into two assemblages (A and B assemblages). Most researchers believe that groups 1 (WB) and $2(\mathrm{JH})$ belong to assemblage A, and group 3 (GS) belongs to assemblage B. ${ }^{19} \mathrm{On}$ the other hand, some believe that group 2 ( $\mathrm{JH}$ isolate) has a close and similar but distinct dependency from assemblage A. ${ }^{21}$

Currently, many molecular studies show that Giardia lamblia is a complex species that consists of at least eight main assemblages (A to $\mathrm{H}$ ), which are morphologically similar but genetically different from each other. ${ }^{22}$ Among these eight assemblages, only assemblages A and B are obtained from humans. These two assemblages can also infect animals. Assemblage A is categorized into smaller genetic groups named AII and AI. Assemblage B also includes smaller genetic groups named BII and BIV. Assemblages $\mathrm{C}$ and $\mathrm{D}$ are specifically for dogs, and it seems that assemblages $\mathrm{E}$, F, G, and $\mathrm{H}$ are specific for livestock, cats, rats, and marine vertebrates such as whales, dolphins, seals and shore birds, respectively. ${ }^{23,24}$

\section{The relation between assembly and clinical signs}

Although the presence of a relation between clinical symptoms and assemblages of Giardia duodenalis has not been confirmed yet ${ }^{25}$ researchers intend to reveal which genotype has a higher effect on diarrheic patients. ${ }^{26}$

\section{Zoonotic transmission (zoonosis)}

Several studies have examined the importance of zoonotic transmission in the occurrence of human giardiasis. ${ }^{27}$ In late 1977, zoonotic potential of Giardia was identified, but this has not been confirmed yet. Possible sources for zoonotic transmission are dairy cattle, dogs, cats, and wild animals. Giardiasis is common among domestic animals (especially cattle and sheep) and infected calves can excrete $10^{5}$ to $10^{6}$ cysts per gram of feces. A European network called NETWORK PROTOZOA ZOONOTIC (ZOOPNET) has evaluated although the majority of human isolates are assemblage B (56\%) and assemblage A (43\%), about one percent of zoonotic assemblage isolates are C, D, E, F. Also a study in Europe shows that assemblage $\mathrm{B}$ is unique for humans, while assemblage $\mathrm{A}$, in addition to humans, appears in dogs, cats, domestic and wild animals. ${ }^{28}$ Studies have shown the concentration of cysts that are excreted in the feces of livestock is more than sewage, although the highest concentration of Giardia cyst is related to sewage. Even though the general prevalence of Giardia is low in wild animals; it is more common in aquatic mammals. ${ }^{4}$

\section{Genotypes of Giardia in animals}

Several studies on livestock-associated Giardia duodenalis have been performed. The results of the studies on Giardia duodenalis positive isolates revealed genotypes A (AI, AII), C, and $\mathrm{E}$ were present in sheep and goats. ${ }^{29-31}$

Also, the study on infected household dogs and cats revealed the presence of genotypes A (AI, AII), C, D, and F. ${ }^{32}$

\section{Prevalence of Giardia in domestic animals}

Various studies have been performed to compare the prevalence of Giardia lamblia infection by age, sex, and diarrhea in infected dogs, cats, rabbits, sheep, goats, and cattle. ${ }^{33-37}$ A significant difference between infection rates in various age groups or between gender was not observed in dogs. ${ }^{33,34}$

While the prevalence of Giardia lamblia is appreciably higher in diarrheic cats, rabbits and cattle compared with non-diarrheic ones. Also the infection is more prevalent in younger animals than older animals. ${ }^{35-37}$ Although these results specified that Giardia duodenalis infection is more prevalent in male prenominate animals compared with female animals, but the difference is not significant. ${ }^{35-37}$ In the study of the abundance of Giardia in Kashan canines, Mohsen Arbabi et al. have reported Giardia canis in dogs and jackals at 5.7\% and 5\%, respectively, and Giardia felis in fox at $22.7 \%{ }^{38}$ Dariush-Shirvani et al. reported the abundance of Giardia among 120 domestic dogs in Isfahan, 4 dogs in a similar study $(3.33 \%) .{ }^{39}$

\section{Geographical distribution of giardiasis and Giardia assemblages in Iran}

Giardiasis is one of the most significant personal and social health problems in different countries. ${ }^{40}$ This disease is endemic in Iran and its average prevalence in different parts is estimated to be $17 \% .{ }^{41}$ Various epidemiological studies have been conducted on the prevalence of Giardia in diverse climatic regions of Iran.

Through the investigations on intestinal and gastrointestinal 
parasites in different regions of Iran, Giardia lamblia has been detected. ${ }^{42-46}$ Giardia duodenalis has been isolated from human stool samples of rural and urban population; ${ }^{47-49}$ Especially in northern and southern areas. ${ }^{50,51}$ In the study in the Boyer-Ahmad district Giardia duodenalis was considered the most common pathogenic protozoan infection. This study revealed associations between protozoan infection and contact with animals and educational status. Findings of this study demonstrated that protozoan infection rate in rural areas of southwestern Iran is still high and remained as a challenging health problem in these areas. ${ }^{52}$ Also in the study on intestinal parasitic infections Giardia duodenalis was the common infection in Chelgerd city. This study revealed that intestinal parasitic infections are more frequent in the tribe populations compared to the inhabitant population. Poor personal hygiene, not washing hands before and after eating, consuming raw food without washing them, play on soil and defecating on it among children and adults and flowing of sewage into rivers are some factors of high prevalence of intestinal protozoa in tribes. ${ }^{53}$ Giardia lamblia has been detected the second most prevalent parasite in Eghbalieh city in Qazvin province and Jiroft city in Kerman province. Socio-economic, geographic, sanitary/hygienic, cultural, and nutritional factors may contribute to the high prevalence of intestinal parasitic infection in these cities. ${ }^{54,55}$ In Takestan district Giardia intestinalis, Blastocystis, and Entamoeba coli were the most prevalent intestinal parasitic infections. Over the past years, causes of intestinal parasitic infections including the level of literacy and health knowledge of people, easy access to antiintestinal parasitic drugs, safe water supply and expansion of drinking water pipeline have improved. At present, it seems that the most important risk factors for intestinal parasitic infections in Iran are eating raw vegetables and close contact to animals. ${ }^{56}$ In southern Iran during 2007-2017 Giardia lamblia has been found the most common parasite. ${ }^{57}$ Giardia lamblia has been determined as the most prevalent parasite in Abadan and Khorramshahr cities during four successive years. ${ }^{58}$ The most infection among diarrheic patients of Ahvaz was Giardia intestinalis. ${ }^{59}$

Giardia duodenalis has been detected in students of Khorramabad. Among the infected students, the most infection belonged to the Laboratory Sciences major (32.43\%) and the fewest infection belonged to the Family Health major $(2.70 \%)$. Most of the infected students were dormitory residents, and this detection is probably due to the sanitary and socioeconomic conditions of this location. ${ }^{60}$ Also Giardia has been found the commonest parasite among the school children of Khorasan province and Golestan province. These studies revealed that the prevalence of parasitic infection increases by family size. Giardiasis infection was the least frequent among those students whose fathers were employer (36.7\%) and the highest prevalent among those students whose fathers were farmer $(61.4 \%) .{ }^{61,62}$ The most frequent parasitic infection among the children in Haji-Abad was Giardia lamblia during 18 years (1991-2008). This conducted study showed that the prevalence of the infection was significantly higher in outpatients. ${ }^{63}$ Among the school children in Sari Giardia lamblia was the second most prevalent parasite. Parasitic infections were negatively associated with contact with soil and eating raw vegetables that were not washed with detergent. ${ }^{64}$ Moreover, among the primary school children of southern Iran Giardia duodenalis was the most prevalent protozoan. The parasitic infection was associated with parents' educational level; The infection was higher among children whose parents' education level was below a high school diploma than those whose parents had at least a high school diploma. ${ }^{65}$ Intestinal parasites have been evaluated in bakery employees in Khorramabad including Giardia intestinalis. The highest para- sitic infections prevalence among the bakery employees belonged to the bakery workers with no health card $(12.3 \%)$ and the least prevalence rate belonged to bakery workers who had health card but were contaminated with intestinal parasites $(11.73 \%) .{ }^{66}$ The commonest intestinal parasite among the food handlers of Sari is Giardia lamblia. Parasitic infections were negatively associated with household income level, contact with dogs and cats, place of living, and eating raw vegetables that were not washed with detergent. Restaurant workers, fast-food workers and fruits/vegetables sellers had the most parasite infection among the food handlers. ${ }^{67}$ In an investigation among the food handlers of western Iran various parasites comprising Giardia duodenalis have been observed. There was a significant difference between validity date of health card, awareness of intestinal parasites transmission, participation in training courses in environmental health with intestinal parasites. ${ }^{68}$ According to a study among the food handlers of Tabriz, Giardia was the prevailing intestinal parasitic infection. The highest percentage of infection is related to restaurants and supermarkets, but in general, there was no statistically significant difference between different professions. ${ }^{69}$ The results of the study among food handlers of Bandar Abbas evinced Giardia lamblia was the third most prevalent intestinal parasite. The least infection was found in the workers of coffee shops while the highest infection was seen in the bakery workers including delivery of bread, bread cooking and cashier. Among the office servants including butlers, chef, and cleaners, the butlers had low contamination but the cleaners had the most. ${ }^{70}$ In the meanwhile, a few food handlers in Saqqez county were infected with Giardia intestinalis. The results indicated that there is no significant correlation between the status of intestinal parasitic infection and the education level or between various occupation. ${ }^{71}$ Giardia lamblia has been observed among the food handlers of Andimeshk. ${ }^{72}$

Multiple intestinal parasitic infections inclusive of Giardia lamblia were prevailing among transplant recipients. According to the results there is no statistically difference in parasitic infections prevalence between renal transplant recipients, comparing to healthy individuals. ${ }^{73}$ Conducted study on the prevalence of intestinal infections among AIDS patients has detected Giardia lamblia. ${ }^{74}$ Besides, the conducted study in diverse groups of immunocompromised patients including cancer and HIV/AIDS patients, Renal Transplant Recipients (PTR), and Hemodialysis Patients (HD) in Qom and Kashan indicated Giardia duodenalis was the most common intestinal parasitic infection. The results of this study showed that intestinal protozoan infections were more frequent among immunocompromised patients, especially in HIV/AIDS and HD. ${ }^{75}$ Although in another research among immunocompromised patients Giardia lamblia existed only in the control group. ${ }^{76}$ The second prevailing intestinal parasitic infection was Giardia duodenalis among cancer patients. ${ }^{77}$ Moreover, Giardia lamblia has been observed among immunocompromised tuberculosis patients. The highest prevalence of IPIs was seen among those TB patients who were positive for HIV, while the less prevalence of IPIs was observed among TB patients who received immunosuppressive drugs. However, statistical significance difference was not observed between presence of intestinal parasites and type of immunodeficiency. ${ }^{78}$ Besides, in patients with irritable bowel syndrome Giardia duodenalis has been detected. The rate of intestinal protozoan infections was higher in patients with IBS compared with control group regarding underlying diseases, and the difference was statistically conspicuous. ${ }^{79}$ The study performed on patients with intestinal protozoan infections diagnosed with salt and pepper retinal lesions has determined the presence of Giardia lamblia. ${ }^{80}$ Examined fecal specimens among mentally retarded 
individuals in Urmia contained five intestinal protozoan species including Giardia lamblia. ${ }^{81}$ According to the research among intellectual disability children Giardia lamblia was the most prevalent species of intestinal parasites. ${ }^{82}$ Among mentally retarded individuals of Bandar-Abbas Giardia lamblia has been observed. ${ }^{83}$ The prevailing protozoan in the mentally disabled population of Rasht was Giardia lamblia as well. The causes of the infection among these patients included illiteracy, consuming raw vegetables and low self-hygiene. ${ }^{84}$ The results of the research on evaluating intestinal parasitic infections among mentally retarded individuals revealed the presence of Giardia lamblia. ${ }^{85}$

An investigation of raw vegetable contamination in the villages of Qazvin has been performed. They found Giardia lamblia cysts in unwashed vegetable samples. ${ }^{86}$ Giardia cysts have been observed in fresh vegetable samples of Tehran as well. ${ }^{87}$

Kia et al. reported the prevalence of this parasite in 21 villages of Mazandaran as $10.2 \% .{ }^{88}$ Sajjadi Study in the rural areas of northern Iran has shown that giardiasis is the highest protozoan infection in preschool children. ${ }^{89}$

In 1993, Sharifi and Keshavarz introduced Giardia as the most common protozoan parasitic infection in 1 to 12 years old children in Kerman. ${ }^{90}$

HIV infection may affect the prevalence of giardiasis. Although Giardia is not considered an opportunistic parasite, its prevalence is higher in AIDS patients. ${ }^{91-93}$ Stool tests of 206 HIVpositive patients at a medical center in Tehran showed Giardia lamblia in $7.3 \%$ of cases. $^{94}$

Taherkhani has reported the frequency of Giardia as $21.41 \%$ in the study of the abundance of intestinal parasites among mentally retarded students of Hamadan in 191 stool samples. ${ }^{95}$ In the study by Molavi et al. in 2009 in rural areas of Khuzestan province, the prevalence of giardiasis was reported at $9.1 \% .{ }^{96}$ The use of molecular methods based on PCR to identify and determine different genotypes of Giardia in stool samples has been increased. So far, few studies have been performed in Iran to determine the genotypes of Giardia lamblia (Appendix Table 2). For the first time in Iran, in 2002, Zare et al. showed that by using the PCR-RELP method, some Giardia isolates from humans can be identified. ${ }^{97}$

In the study of Babaei et al., out of 38 studied samples, 33 samples of AII assemblage, and 3 samples of BIII assemblages, and 2 samples of mixed AII and BIII infections were reported. These findings show that in Tehran, Giardia infection was of human origin and is mostly AII assemblage and human is a reservoir of infection. ${ }^{98}$ A similar study was conducted in 2008 by Fallah et al. in East Azerbaijan to determine the genotype of Giardia in humans, cats, dogs, and cattle, and the GDH gene was used to determine the genotype. Among human samples, 8 samples of assemblage BIII, six samples of assemblage AII, and 4 samples of assemblage BIV and among animal samples (1 cat) AI assemblage were obtained. ${ }^{99}$ In another investigation by Etemadi et al. in Kerman on the GDH gene, out of 30 studied samples, 18 AII assemblage samples, five AI assemblage samples, and 7 BIII assemblage samples were reported. ${ }^{100}$ Nahavandi et al. conducted a study in Tabriz in 2011. In this study, 34 positive stool samples were collected for Giardia lamblia and the PCR-RELP method was used to identify the diversity of TPI genes. In using the TPI gene in this study, 13 samples (41.9\%) were from genotype B, 17 samples $(54.8 \%)$ were from genotype A and 1 sample (3.2\%) was from both genotypes and 3 samples $(8.8 \%)$ were negative. The results show that PCR is a convenient method of diagnosing fecal contamination. ${ }^{101}$ Akbarian et al. studied the genetic differences of Giardia lamblia in Khorramabad city and surrounding villages using PCR and determining the sequence. The GDH gene amplification was successful- ly performed by PCR in only 24 out of 30 parasitic fecal samples. Alignment of the obtained GDH sequence with the gene bank sequences was performed and a total of 5 samples ( 3 urban samples and 2 rural samples) were a sequence that all of them were genotype B and no difference was observed between them. ${ }^{102}$ In the Sarkari et al. study, among 172 positive samples of Giardia, 128 samples (74.1\%) assemblage AII, 30 samples (17.44\%) assemblage BIII, six samples (3.49\%) assemblage BIV and 8 samples (4.66\%) Mixed (BIII and AII) were reported. ${ }^{103}$ In Manouchehri et al., investigation, PCR showed that in patients, the frequency of Giardia B genotype was higher than A genotype $(51.6 \%$ vs. $35.5 \%$ ). However, the frequency of genotype A was significantly higher among patients with diarrhea compared to asymptomatic patients. ${ }^{104}$

In the end, it can be concluded that according to the studies conducted in different parts of Iran, assemblages BIII and AII are the most common type of Giardia, respectively (Appendix Table 2). $25,49,52,55,99-125$

There is also no clear correlation between Giardia lamblia assemblages and clinical signs, and the results of the study are contradictory. Limited studies on different genotypes of Giardia in Iran show that the most suitable target gene for genotypic studies is glutamate dehydrogenase (GDH).

Giardia infection probably transmits in both human-animal and human-human ways in Iran, and the possibility of Giardia lamblia being zoonotic in Iran is also raised. Therefore, comprehensive studies on humans and different animal isolates in different parts of the country, especially in areas where no research has been done, seem necessary.

\section{References}

1. Lalle M, Pozio E, Capelli G, et al. Genetic heterogeneity at the beta-giardin locus among human and animal isolates of Giardiaduodenalis and identification of potentially zoonotic subgenotypes. Int J Parasitol 2005;35:207-13.

2. Fricker C, Medema G, Smith H. Protozoan parasites (Cryptosporidium, Giardia, Cyclospora). Guidelines for Drinking-Water Quality 2002;2:70-118.

3. Hardy S. Topley and Wilson's Microbiology and Microbial Infections: Parasitology. Br J Biomed Sci 2007;64:190.

4. Thompson RC. The zoonotic significance and molecular epidemiology of Giardia and giardiasis. Vet Parasitol 2004;126:15-35.

5. Behrman RE, Kliegman R, Nelson WE. Nelson textbook of pediatrics. Philadelphia: W.B. Saunders; 1996.

6. Prucca CG, Slavin I, Quiroga R, et al. Antigenic variation in Giardia lamblia is regulated by RNA interference. Nature 2008;456:750-4.

7. Koot BG, ten Kate FJ, Juffrie M, et al. Does Giardia lamblia cause villous atrophy in children?: A retrospective cohort study of the histological abnormalities in giardiasis. J Pediatr Gastroenterol Nutr 2009;49:304-8.

8. Adam RD. Biology of Giardia lamblia. Clin Microbiol Rev 2001;14:447-75.

9. Kamda JD, Singer SM. Phosphoinositide 3-kinase-dependent inhibition of dendritic cell interleukin-12 production by Giardia lamblia. Infect Immun 2009;77:685-93.

10. Astiazaran-Garcia H, Quintero J, Vega R, et al. Identification of T-cell stimulating antigens from Giardia lamblia by using Giardia-specific T-cell hybridomas. Parasite Immunol 2009;31:132-9. 
11. Andersen YS, Gillin FD, Eckmann L. Adaptive immunitydependent intestinal hypermotility contributes to host defense against Giardia spp. Infect Immun 2006;74:2473-6.

12. Fraser D, Bilenko N, Deckelbaum RJ, et al. Giardia lamblia Carriage in Israeli Bedouin Infants: Risk Factors and Consequences. Clin Infect Dis 2000;30:419-24.

13. Quihui-Cota L, Astiazarán-García $\mathrm{H}$, Valencia ME, et al. Impact of Giardia intestinalis on vitamin a status in schoolchildren from northwest Mexico. Int J Vitam Nutr Res 2008;78:51-6.

14. Müller J, Ley S, Felger I, et al. Identification of differentially expressed genes in a Giardia lamblia WB C6 clone resistant to nitazoxanide and metronidazole. J Antimicrob Chemother 2008;62:72-82.

15. Saffar MJ, Qaffari J, Khalilian AR, Kosarian M. Rapid reinfection by Giardia lamblia after treatment in a hyperendemic area: the case against treatment. East Mediterr Health J 2005;11:73-8.

16. Gilman R, Miranda E, Marquis G, et al. Rapid reinfection by Giardia lamblia after treatment in a hyperendemic third world community. Lancet 1988;331:343-5.

17. Shukla G, Devi P, Sehgal R. Effect of Lactobacillus casei as a Probiotic on Modulation of Giardiasis. Digest Dis Sci 2008;53:2671-9.

18. Upton SJ, Zien CA. Description of a Giardia varani-like flagellate from a water monitor, Varanus salvator, from Malaysia. J Parasitol 1997;83:970-1.

19. Monis PT, Mayrhofer G, Andrews RH, et al. Molecular genetic analysis of Giardia intestinalis isolates at the glutamate dehydrogenase locus. Parasitology 1996;112:1-12.

20. Lu S, Wen J, Li J, Wang F. DNA sequence analysis of the triose phosphate isomerase gene from isolates of Giardia lamblia. Chin Med J (Engl) 2002;115:99-102.

21. Sulaiman IM, Fayer R, Bern C, et al. Triosephosphate Isomerase Gene Characterization and Potential Zoonotic Transmission of Giardia duodenalis. Emerg Infect Dis J 2003;9:1444

22. Thompson RC, Monis PT. Variation in Giardia: implications for taxonomy and epidemiology. Adv Parasitol 2004;58:69137.

23. Thompson RC, Meloni BP. Molecular variation in Giardia. Acta Trop 1993;53:167-84.

24. Lasek-Nesselquist E, Welch DM, Sogin ML. The identification of a new Giardia duodenalis assemblage in marine vertebrates and a preliminary analysis of G. duodenalis population biology in marine systems. Int J Parasitol 2010;40:1063-74.

25. Rafiei A, Roointan ES, Samarbafzadeh AR, et al. Investigation of possible correlation between Giardia duodenalis genotypes and clinical symptoms in southwest of Iran. Iran J Parasitol 2013;8:389-95.

26. Pestechian N, Rasekh H, Rostami-Nejad M, Yousofi HA, Hosseini-Safa A. Molecular identification of Giardia lamblia; is there any correlation between diarrhea and genotyping in Iranian population? Gastroenterol Hepatol Bed Bench 2014;7:168-72.

27. Hoque ME, Hope VT, Kjellström T, Scragg R, Lay-Yee R. Risk of giardiasis in Aucklanders: a case-control study. Int $\mathrm{J}$ Infect Dis 2002;6:191-7.

28. Sprong H, Cacciò SM, van der Giessen JW. Identification of zoonotic genotypes of Giardia duodenalis. PLoS Negl Trop Dis 2009;3:e558.

29. Jafari H, Jalali MHR, Shapouri MSA, Hajikolaii MRH. Determination of Giardia duodenalis genotypes in sheep and goat from Iran. J Parasit Dis 2014;38:81-4.

30. Faridi A, Kareshk A, Sadooghian S, Firouzeh N. Frequency of different genotypes of Giardia duodenalis in slaughtered sheep and goat in east of iran. J Parasitic Dis 2020;44.

31. Kiani-Salmi N, Fattahi-Bafghi A, Astani A, Sazmand A, Zahedi A, Firoozi Z, et al. Molecular typing of Giardia duodenalis in cattle, sheep and goats in an arid area of central Iran. Infect Genet Evol 2019;75:104021.

32. Homayouni MM, Razavi SM, Shaddel M, Asadpour M. Prevalence and molecular characterization of Cryptosporidium spp. and Giardia intestinalis in household dogs and cats from Shiraz, Southwestern Iran. Vet Ital 2019;55:311-8.

33. Gharekhani J. Study on gastrointestinal zoonotic parasites in pet dogs in Western Iran. Turkiye Parazitol Derg 2014;38:1726.

34. Kohansal MH, Fazaeli A, Nourian A, Haniloo A, Kamali K. Dogs' gastrointestinal parasites and their association with public health in Iran. J Vet Res 2017;61:189-95.

35. Mosallanejad B, Avizeh R, Razi Jalali MH. Detection of Giardia duodenalis antigen in companion rabbits of Ahvaz district, South-West of Iran. Iranian J Vet Sci Technol 2016;8:58-63.

36. Mosallanejad B, Avizeh R, Jalali MR, Alborzi A. Prevalence of Giardia duodenalis infection in household cats of Ahvaz District, south-west of Iran. Iran J Parasitol 2010;5:27-34.

37. Malekifard F, Ahmadpour M. Molecular detection and identification of Giardia duodenalis in cattle of Urmia, northwest of Iran. Vet Res Forum 2018;9:81-5.

38. Arbabi M, Doroodgar A, Hoshyar H, Asadi MA. Evaluation of Giardia and Sarcocystis contamination in dog-related animals in Kashan region during the years 1999-2001. KAUMS J (FEYZ) 2001;5:83-9.

39. Shirani D, Khalili M, Meshki B. The prevalence of giardia in fection in companion dogs, Esfahan. J Tehran Univ Vet Res 2006;61:161-3.

40. Organization WH. Prevention and control of intestinal parasitic infections: report of a WHO Expert Committee [meeting held in Geneva from 3 to 7 March 1986]: World Health Organization; 1987.

41. Fakhar M, Kialashaki E, Sharif M. An Overview on the present Situation of Giardiasis in Iran and the World with Emphasis on Zoonotic Aspects. J Mazandaran Univ Med Sci 2014;24:235-51.

42. Hemmati N, Razmjou E, Hashemi-Hafshejani S, et al. Prevalence and Risk Factors of Human Intestinal Parasites in Roudehen, Tehran Province, Iran. Iran $\mathrm{J}$ Parasitol 2017;12:364-73.

43. Vahedi M, Gohardehi S, Sharif M, Daryani A. Prevalence of parasites in patients with gastroenteritis at East of Mazandaran Province, Northern Iran. Trop Biomed 2012;29:568-74.

44. Kiani H, Haghighi A, Rostami A, Azargashb E, Seyyedtabaei S, Solgi A, et al. Prevalence, risk factors and symptoms associated to intestinal parasite infections among patients with gastrointestinal disorders in Nahavand, Western Iran. Revista do Instituto de Medicina Tropical de São Paulo 2016;58.

45. Norouzi P, Mohaghegh M-A, Ghorbani M, et al. Investigating the prevalence of intestinal parasites with an emphasis on Strongyloides stercoralis infection in hospitalized patients: a regional report from Iran. Ann Parasitol 2020;66:365-71.

46. Abbaszadeh Afshar MJ, Barkhori Mehni M, Rezaeian M, et al. Prevalence and associated risk factors of human intestinal 
parasitic infections: a population-based study in the southeast of Kerman province, southeastern Iran. BMC Infect Dis 2020;20:12.

47. Kuzehkanani AB, Rezaei S, Babaei Z, et al. Enteric protozoan parasites in rural areas of bandar-abbas, southern iran: comparison of past and present situation. Iranian J Public Health 2011;40:80-5.

48. Sharifdini M, Ghanbarzadeh L, Barikani A, Saraei M. Prevalence of Intestinal Parasites among Rural Inhabitants of Fouman, Guilan Province, Northern Iran with Emphasis on Strongyloides stercoralis. Iran J Parasitol 2020;15:91-100.

49. Jafari R, Sharifi F, Bagherpour B, Safari M. Prevalence of intestinal parasites in Isfahan city, central Iran, 2014. J Parasit Dis 2016;40:679-82.

50. Pagheh AS, Sharif M, Daryani A, et al. A cross-sectional analysis of intestinal parasitic infections among the general population in north of Iran. J Infect Devel Countries 2018;12(2):120-6.

51. Sobati H. Epidemiological study of parasitic infections in BuMusa Island, Hormozgan. Iran J Parasitol 2020;15:425-34.

52. Sarkari B, Hosseini G, Motazedian MH, et al. Prevalence and risk factors of intestinal protozoan infections: a populationbased study in rural areas of Boyer-Ahmad district, Southwestern Iran. BMC Infect Dis 2016;16:703.

53. Pestehchian N, Nazari M, Haghighi A, et al. Prevalence of intestinal parasitic infection among inhabitants and tribes of Chelgerd, Iran, 2008-2009. J Clin Diagn Res 2015;9:LC01-4.

54. Sadeghi H, Bakht M, Saghafi H, Shahsavari T. Prevalence of intestinal parasites in a population in Eghbalieh city from Qazvin Province, Iran. J Parasit Dis 2015;39:126-9.

55. Barkhori Mahni M, Rezaeian M, Kia EB, et al. Prevalence of Intestinal Parasitic Infections in Jiroft, Kerman Province, Iran. Iran J Parasitol 2016;11:232-8.

56. Taherkhani K, Barikani A, Shahnazi M, Saraei M. Prevalence of Intestinal Parasites among Rural Residents of Takestan in North-West of Iran. Iran J Parasitol 2019;14:657-63.

57. Alasvand Javadi R, Kazemi F, Fallahizadeh S, Arjmand R. The Prevalence of Intestinal Parasitic Infections in Ahvaz, Southwest of Iran, during 2007-2017. Iran J Public Health 2019;48:2070-3.

58. Soltani S, Salmanzadeh S, Soltani S, et al. Prevalence of Intestinal Parasitic Infections in the Southwest of Iran: A Four-year Retrospective Study. Infect Disord Drug Targets 2020;20:854-9.

59. Karami S, Beiromvand M, Kohansal K. Prevalence of intestinal parasitic infections among diarrheic patients from Ahvaz, southwestern Iran. Infect Disord Drug Targets 2020: doi: 10.2174/1871526520999201116202411. Online ahead of print.

60. Fallahi S, Rostami A, Mohammadi M, Ebrahimzadeh F, Pournia Y. Practical parasitology courses and infection with intestinal parasites in students. J Infect Public Health 2016;9:654-60.

61. Taheri F, Namakin K, Zarban A, Sharifzadeh G. Intestinal Parasitic Infection among School Children in South Khorasan Province, Iran. J Res Health Sci 2011;11:45-50.

62. Masoumeh R, Farideh T, Mitra S, Heshmatollah T. Intestinal parasitic infection among school children in Golestan province, Iran. Pak J Biol Sci 2012;15:1119-25.

63. Ashtiani MTH, Monajemzadeh M, Saghi B, et al. Prevalence of intestinal parasites among children referred to Children's Medical Center during 18 years (1991-2008), Tehran, Iran. Ann Trop Med Parasitol 2011;105:507-12.
64. Daryani A, Sharif M, Nasrolahei M, Khalilian A, Mohammadi A, Barzegar G. Epidemiological survey of the prevalence of intestinal parasites among schoolchildren in Sari, northern Iran. Trans Royal Soc Trop Med Hygiene 2012;106:455-9.

65. Turki H, Hamedi Y, Heidari-Hengami M, et al. Prevalence of intestinal parasitic infection among primary school children in southern Iran. J Parasit Dis 2017;41:659-65.

66. Kheirandish F, Tarahi M, Haghighi A, et al. Prevalence of intestinal parasites in bakery workers in khorramabad, lorestan iran. Iran J Parasitol 2011;6:76-83.

67. Sharif M, Daryani A, Kia E, et al. Prevalence of intestinal parasites among food handlers of Sari, Northern Iran. Rev Inst Med Trop Sao Paulo 2015;57:139-44.

68. Kheirandish F, Tarahi MJ, Ezatpour B. Prevalence of intestinal parasites among food handlers in Western Iran. Rev Inst Med Trop Sao Paulo 2014;56:111-4.

69. Balarak D, Modrek MJ, Bazrafshan E, et al. Prevalence of intestinal parasitic infection among food handlers in northwest Iran. J Parasitol Res 2016;2016:8461965.

70. Heydari-Hengami M, Hamedi Y, Najafi-Asl M, SharifiSarasiabi K. Prevalence of intestinal parasites in food handlers of Bandar Abbas, southern Iran. Iran J Public Health 2018;47:111-8.

71. Shahnazi M, Abdollahpour H, Alipour M, et al. Prevalence of intestinal parasites in food handlers of the city of Saqqez in 2016. J Parasit Dis 2019;43:113-9.

72. Beiromvand M, Mirrezaie E, Mirzavand S. Foodborne Giardiasis: Is there any relationship between food handlers and transmission of Giardia duodenalis? Infect Disord Drug Targets 2017;17:72-6.

73. Azami M, Sharifi M, Hejazi SH, Tazhibi M. Intestinal parasitic infections in renal transplant recipients. Braz J Infect Dis 2010;14:15-8.

74. Agholi M, Hatam GR, Motazedian MH. HIV/AIDS-associated opportunistic protozoal diarrhea. AIDS Res Hum Retroviruses 2013;29:35-41.

75. Rasti S, Hassanzadeh M, Hooshyar H, et al. Intestinal parasitic infections in different groups of immunocompromised patients in Kashan and Qom cities, central Iran. Scand J Gastroenterol 2017;52:738-41.

76. Mahmoudi MR, Hasani H, Tsiami A, et al. Intestinal protozoan and helminthic infections among hemodialysis and cancer patients. Parasitol Res 2020;119:3053-9.

77. Esteghamati A, Khanaliha K, Bokharaei-Salim F, et al. Prevalence of intestinal parasitic infection in cancer, organ transplant and primary immunodeficiency patients in Tehran, Iran. Asian Pac J Cancer Prev 2019;20:495-501.

78. Taghipour A, Azimi T, Javanmard E, et al. Immunocompromised patients with pulmonary tuberculosis; a susceptible group to intestinal parasites. Gastroenterol Hepatol Bed Bench 2018;11:S134-s9.

79. Shafiei Z, Esfandiari F, Sarkari B, et al. Parasitic infections in irritable bowel syndrome patients: evidence to propose a possible link, based on a case-control study in the south of Iran. BMC Res Notes 2020;13:1-5.

80. Jafari R, Gorgizadeh H, Soosaraei M, et al. Initial Evidences of Salt and Pepper Retinal Lesions (SPRL) in Patients with Intestinal Protozoan Infections in Iran. Infect Dis Drug Targets 2021;21:60-7.

81. Tappeh Kh H, Mohammadzadeh H, Rahim RN, et al. Prevalence of intestinal parasitic infections among mentally disabled children and adults of Urmia, Iran. Iran J Parasitol 2010;5:60-4. 
82. Sharif M, Daryani A, Asgarian F, Nasrolahei M. Intestinal parasitic infections among intellectual disability children in rehabilitation centers of northern Iran. Res Dev Disabil 2010;31:924-8.

83. Shokri A, Sarasiabi KS, Teshnizi SH, Mahmoodi H. Prevalence of Strongyloides stercoralis and other intestinal parasitic infections among mentally retarded residents in central institution of southern Iran. Asian Pac J Trop Biomed 2012;2:88-91.

84. Saeidinia A, Tavakoli I, Naghipour MR, et al. Prevalence of Strongyloides stercoralis and other intestinal parasites among institutionalized mentally disabled individuals in Rasht, Northern Iran. Iran J Parasitol 2016;11:527-33.

85. Mohammadi-Meskin V, Hamedi Y, Heydari-Hengami M, et al. Intestinal parasitic infections in mental retardation center of Bandar Abbas, Southern Iran. Iran J Parasitol 2019;14:31825.

86. Shahnazi M, Jafari-Sabet M. Prevalence of parasitic contamination of raw vegetables in villages of Qazvin Province, Iran. Foodborne Pathog Dis 2010;7:1025-30.

87. Isazadeh M, Mirzaii-Dizgah I, Shaddel M, Homayouni MM. The prevalence of parasitic contamination of fresh vegetables in Tehran, Iran. Turkiye Parazitol Derg 2020;44:143-8.

88. Kia EB, Hosseini M, Nilforoushan MR, et al. Study of intestinal protozoan parasites in rural inhabitants of Mazandaran Province, Northern Iran. Iran J Parasitol 1970;3.

89. Sadjjadi S, Massoud J. Prevalence pattern of Giardia lamblia in the rural areas in the north of Iran. Giardia from Molecules to Diseases 1994:365.

90. Sharifi I, Keshavarz H. The prevalence of intestinal in 1 to 11 year old children in Kerman. J Drug Treat 1993;121:7-11.

91. Sharafi M. Prevalence of intestinal parasites in student of elementary school, Bandar Abbas. J Hormoz Univ Med Sci 2011;29:4.

92. Mohandas, Sehgal R, Sud A, Malla N. Prevalence of Intestinal Parasitic pathogens in HIV-Seropositive Individuals in Northen India. Jpn J Infect Dis 2002;55:83-4.

93. Gautam H, Bhalla P, Saini S, et al. Epidemiology of opportunistic infections and its correlation with CD4 T-lymphocyte counts and plasma viral load among HIV-positive patients at a tertiary care hospital in India. J Int Ass Physicians AIDS Care 2009;8:333-7.

94. Zali MR, Mehr AJ, Rezaian M, et al. Prevalence of intestinal parasitic pathogens among HIV-positive individuals in Iran. Jpn J Infect Dis 2004;57:268-70.

95. Taherkhani H. Prevalence of intestinal parasites in mentally disabled students in Hamedan 2000. Jundishapur Sci Med J 2002;32:58-63.

96. Mowlavi G, MirAhmadi H, Rezaeian M, et al. Prevalence of intestinal parasites in tribal parts of Khuzestan Province during 2005-07. Govaresh 2012;12:10.

97. Zare Bavani M, Rezaian M, Jedi Tehrani M, Kazemi B. Application of PCR-RFLP for identification of Giardia isolates of human in Iran. Cell Journal (Yakhteh) 2002;4.

98. Babaei Z, Oormazdi H, Akhlaghi L, et al. Molecular characterization of the Iranian isolates of Giardia lamblia: application of the glutamate dehydrogenase gene. Iranian J Publ Health 2008;37:75-82.

99. Fallah E, Nahavandi KH, Jamali R, et al. Molecular identification of Giardia duodenalis isolates from human and animal reservoirs by PCR-RFLP. J Biol Sci 2008;8:896-901.

100. Etemadi S, Ziyaali N, Babaei Z, et al. The correlation between clinical signs and genotypes of Giardia duodenalis isolated from patients with Giardiasis in Kerman City. J Kerman Univ Med Sci 2011;18:330-9.

101. Nahavandi KH, Fallah E, Asgharzadeh M, et al. Glutamate dehydrogenase and triose-phosphate-isomerase coding genes for detection and genetic characterization of Giardia lamblia in human feces by PCR and PCR-RFLP. Turkish J Med Sci 2011;41:283-9.

102. Akbarian A, Sadraie J, Forozandeh M. Evaluattion of Giardia lamblia genetic differences in Khorramabad City and surrounding villages by use of PCR and sequencing. Sci J Kurdistan Univ Med Sci 2012;17:61-71.

103. Sarkari B, Ashrafmansori A, Hatam GR, et al. Genotyping of Giardia lamblia isolates from human in southern Iran. Trop Biomed 2012;29:366-71.

104. Manouchehri Naeini K, Hosseini SA, Gholipour A, et al. Genotyping of Giardia duodenalis isolates in individuals with and without chronic diarrhea using Polymerase Chain Reaction. J Mazandaran Univ Med Sci 2012;22:39-46.

105. Rayani M, Hatam G, Unyah NZ, et al. Phylogenetic analysis of Giardia lamblia human genotypes in Fars Province, southern Iran. Iran J Parasitol 2017;12:522-33.

106. Kialashaki E, Fakhar M, Sharif M, et al. The mixed AII and BIII genotypes of human Giardia lamblia isolate circulating in Mazandaran Province, Northern Iran. Infect Disord Drug Targets 2020;20:834-9.

107. Roointan ES, Rafiei A, Samarbaf-Zadeh AR, et al. Molecular identification of Giardia lamblia isolates from adult human cases in southwest of Iran. Afr J Biotechnol 2013;12:901-6.

108. Pestehchian N, Rasekh H, Babaei Z, et al. Identification of genotypes of Giardia duodenalis human isolates in Isfahan, Iran, using polymerase chain reaction - Restriction Fragment Length polymorphism. Adv Biomed Res 2012;1:84.

109. Hazrati Tappeh K, Manafi G, Asgharzadeh M, Manafi F. Incidence of Giardia lamblia Subspecies by PCR-RFLP in Stool Specimens of Hospitalized Children at Urmia Mutahhari Hospital, West Azerbaijan Province, Iran. Iran J Parasitol 2014;9:541-7.

110. Mirzavand S, Kohansal K, Beiromvand M. Molecular genotyping of Giardia duodenalis in municipal waste workers in Ahvaz, southwestern Iran. Trop Biomed 2019;36:44-52.

111. Kashinahanji M, Haghighi A, Bahrami F, et al. Giardia lamblia assemblages $\mathrm{A}$ and $\mathrm{B}$ isolated from symptomatic and asymptomatic persons in Hamadan, west of Iran. J Parasit Dis 2019;43:616-23.

112. Rahimian F, Sadraei J, Pirestani M, Ghaffarifar F. A modified PCR-RFLP method to determine genetic diversity of Giardia lamblia human isolates based on triosephosphate isomerase (TPI) gene. Acta Trop 2018;186:58-62.

113. Hooshyar H, Ghafarinasab S, Arbabi M, et al. Genetic variation of Giardia lamblia isolates from food-handlers in Kashan, Central Iran. Iran J Parasitol 2017;12:83-9.

114. Shahdoust S, Niyyati M, Haghighi A, et al. Prevalence of intestinal parasites in referred individuals to the medical centers of Tonekabon city, Mazandaran province. Gastroenterol Hepatol Bed Bench 2016;9:S75-S9.

115. Shahnazi M, Naghizadeh F, Hajialilo E, et al. Investigation of Giardia intestinalis Genotypes among the Food Handlers of Qazvin, Iran. Iran J Parasitol 2019;14:534-41.

116. Nasiri Goorabi L, Pirestani M, Sadraei J. Genotyping of Giardia Duodenalis by $\beta$-giardin gene in asymptomatic patients. J Mazandaran Univ Med Sci 2017;27:27-34.

117. Effati F, Dalimi AH, Pirestani M. A survey on Giardia and Cryptosporidium infection and genotyping common Giardia 
in children in Alborz Province. Pathobiol Res 2018;21:133-9.

118. Siyadatpanah A, Sharif M, Daryani A, et al. Spatial distribution of Giardia lamblia infection among general population in Mazandaran Province, north of Iran. J Parasit Dis 2018;42:171-6.

119. Sepahvand A, Hosseini-Safa A, Yousofi HA, Tajedini MH, Gharehbabah RP, Pestehchian N. Genotype Characteristics of Giardia duodenalis in Patients Using High Resolution Melting Analysis Technique in Khorramabad, Iran. Iran J Parasitol 2020;15:204.

120. Kasaei R, Carmena D, Jelowdar A, Beiromvand M. Molecular genotyping of Giardia duodenalis in children from Behbahan, southwestern Iran. Parasitol Res 2018;117:1425-31.

121. Mahmoudi MR, Mahdavi F, Ashrafi K, et al. Report of Giardia assemblages and giardiasis in residents of Guilan province-Iran. Parasitol Res 2020;119:1083-91.
122. Bahrami F, Zamini GH, Haghighi A, Khademerfan MB. Detection and molecular identification of human giardia isolates in the west of Iran. Biomed Res (India) 2017;28:568792.

123. Ayatollahi J, Mousavi SA, Hafizi M, et al. The Prevalence of Intestinal Parasites in the Samples Collected from the Central Laboratory of Borujen, Iran. Jentashapir J Cell Mol Biol 2018;9:e83692.

124. Rafiei A, Roointan ES, Samarbafzadeh AR, et al. Investigation of possible correlation between Giardia duodenalis genotypes and clinical symptoms in southwest of Iran. Iran J Parasitol 2013;8:389-95.

125. Mirrezaie E, Beiromvand M, Tavalla M, Teimoori A, Mirzavand S. Molecular Genotyping of Giardia duodenalis in Humans in the Andimeshk County, Southwestern Iran. Acta Parasitologica 2019;64:376-83. 